ORIGINAL ARTICLE

\title{
Investigating the attitudes of special educated physical education prospective teachers towards disabled people
}

\author{
Emrah Aykora ${ }^{\mathrm{ABCDE}}$, Sinan Uğraş ${ }^{\mathrm{ABCDE}}$ \\ University of Çanakkale Onsekiz Mart, Çanakkale, Turkey \\ Authors' Contribution: A - Study design; B - Data collection; C - Statistical analysis; D - Manuscript Preparation; \\ E - Funds Collection.
}

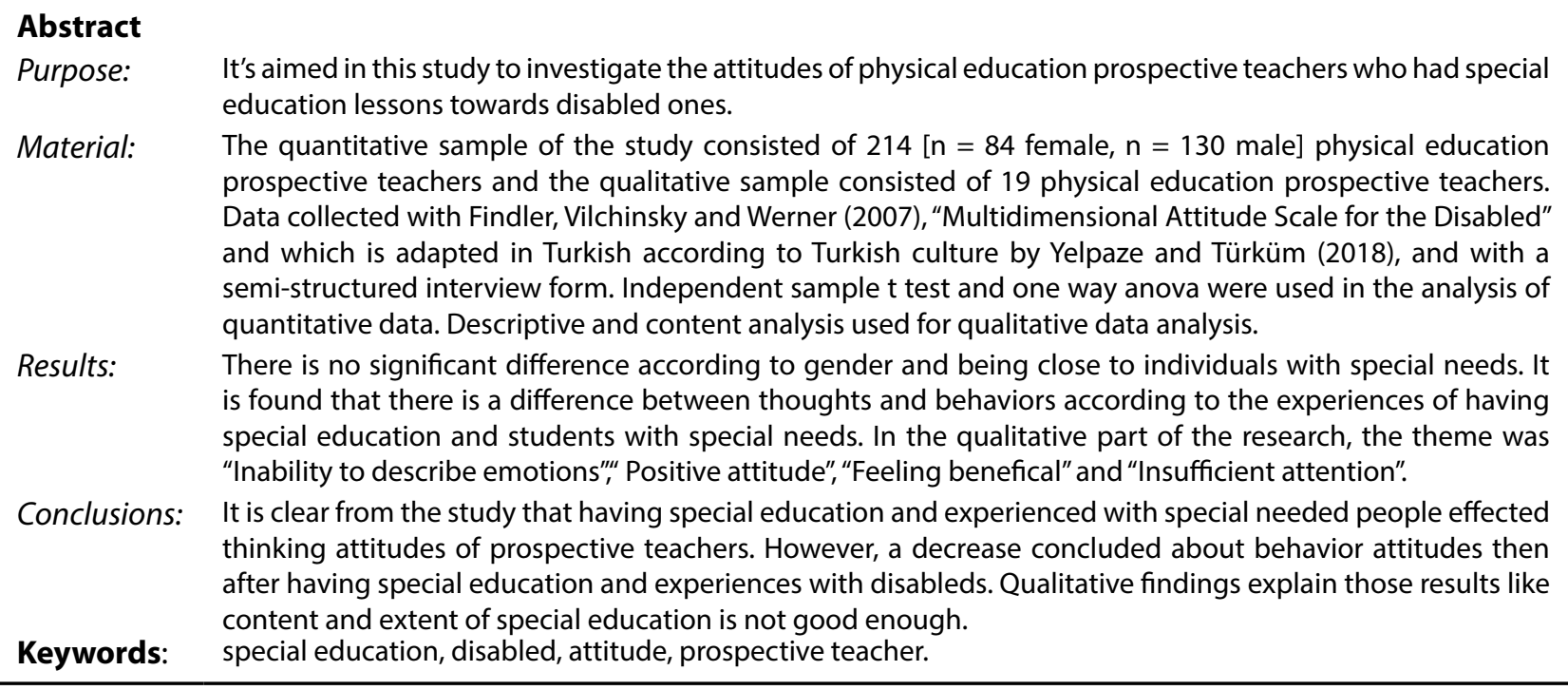

\section{Introduction}

Our definition of disability affects from our relationship with disableds and past experience all we had. The general belief about disability is a mentalphysical disorder that limits and restricts the individual's activities of life and occurs as a limitation-deficiency in the individual's abilities and strength $[1,2]$. In this regard, the World Health Organization (WHO) made a general definition and pointed out that disability is the deficiency or limitation of the normal activities, which are expressed as behaviors expected from the person or the body as a whole, abilities and tasks [3]. Finkelstein [4] commented that being disabled means being discriminated against, including social isolation and restriction. Again, the World Health Organization has identified disability as stigmatization, discrimination and inequalities, even leading to a lower standard of living and poverty due to lack of access to education and employment [5]. At that point it comes forefront increasing the life standards of disabled people and the importance of education. Disabled people should be able to attend public or private educational institutions which is suitable over their disability. It legalized with the name of Special Education in 1997 and shaped by the Special Education Services Regulation in 2006. In the final form, it has been called inclusion education and a situation has been realized in which individuals who need special education can receive their education together with their peers without disability. The number of individuals with special needs in Turkey (c) Emrah Aykora, Sinan Uğraş, 2020 doi:10.15561/20755279.2020.0102
295697 it is stated that according to statistics from 2018 to 2019 [6]. The fact that this number is considerably large increases the likelihood that all teachers may encounter children who require special education one or more times in their professional lives. With the introduction of inclusive education, teachers should be able to deal with both children with disabilities and other children in the classroom. In a study conducted by Sucuoğlu and Kargin [7], they stated that they should have the necessary knowledge and skills in terms of adapting classroom physical environment, program and teaching methods to different requirements and using effective classroom management techniques in addition to having positive attitudes of the classroom teacher. Teachers should take an attitude that does not cause weakness in the classroom with a correct approach in case of unexpected behavior from students with disabilities. Undoubtedly, these and similar situations may be more difficult for teachers who encounter students with disabilities through inclusion education for the first time than teachers who are directly trained in special education teacher programs.

Like normal children, children with disabilities have biological, social and psychological needs such as eating, drinking, loving, being liked, being accepted, being successful. Physical education and sport activities are an area that enables individuals with disabilities to control their emotions such as aggression, anger and jealousy that arise as a result of both their mood and the society's attitudes towards them [8]. Koçyiğit et.al., [9] said that the energy contained in the organism is spent through 
purposeful activities and purposeful activities. Parallel to this, the power that is not spent with sports activities, ie games, can be used negatively and cause aggressive tendencies. For this reason, Physical Education course is an important lesson for all children with disabilities.

It is a fact that teachers face many problems related to inclusive education. These problems are insufficient physical conditions [10], lack of time [11], lack of knowledge of teachers [12], insufficient in-service training [13] and problems in classroom management [14]. When the literature is examined, there are studies indicating that teachers have negative attitudes towards inclusive education $[15,16,17]$. This is due to problems and lack of undergraduate education or insufficient $[18,19]$. Many studies have found that the scope of special education courses in undergraduate education is insufficient. It has been emphasized that there are problems in communicating with individuals with special needs in studies related to prospective teachers [20] and that the scope of inclusion and special education course is insufficient [21,22]. When the studies on physical education and sports teacher candidates with special needs are examined, it is stated that they have positive attitudes about individuals with special needs [23, 24]. In their study, Açak et.al., [25] found a decrease in attitudes towards individuals with disabilities as the level of class increased. There is a parallel between our study results and our research.

In this context, it is obligated to question the adequacy of only two-hours Special Education lesson, which has been taught in Physical Education and Sports Teaching Departments in the previous years as Physical Education and Sports for Disabled students. For this purpose, the effect of special education lesson on emotional, thought and behavior attitudes towards individuals with special needs was investigated in the scope of this research.

In this study, it is aimed to examine the attitudes of physical education and prospective sports teachers about individuals with special needs with quantitative and qualitative data according to their experience of taking special education lessons and special needs students.

\section{Material and Method}

\section{Research pattern}

In order to determine the attitudes and thoughts of the students attending the Department of Physical Education and Sports Teaching to individuals with special needs, a parallel pattern converging from mixed research methods was used. In this research design, qualitative and quantitative data are collected simultaneously and analyzed separately. Subsequently, the findings are interpreted together equally [26]. In this research method, researchers can change the prioritization of qualitative or quantitative data. In this context, taking special education lesson in quantitative variables, having experience with individuals with special needs and gender variables were examined. In parallel to the quantitative variable, 3 different focus groups were formed according to the status of taking special education courses and having experience. Both quantitative and qualitative data were collected by the researchers at the same time. The quantitative and qualitative data obtained from the prospective physical education teachers were interpreted together.

\section{Research group}

The research was conducted in 2018-2019 academic year. The quantitative research group of the students who participated in the study consisted of 214 students as $60.7 \%(n=130)$ male students and $39.3 \%(n=84)$ female students studying in Physical Education and Sports Teaching Department of Bitlis Eren University and Çanakkale Onsekiz Mart University. 38.3\% $(\mathrm{n}=82)$ of the students who did not take the Special Education lesson, $39.3 \%(n=84)$ of the students who took the special education course and the students with special needs and the students who had experience in teaching practice constituted $22.4 \%(n=48)$ of the research.

The qualitative part of the study was determined by criterion sampling method. According to this sampling method, it is required that the researcher is based on certain criteria in advance or meets certain criteria in advance [27]. In this research, as a criterion, taking special education course and being in contact with students with special needs in teaching practice course were taken as basis. Separate focus group interviews were conducted with the students participating in the research. The first focus group consisted of 6 students who did not take special education courses. The second focus group interview was attended by 7 students who took the special education course, and the third focus group interview was attended by 6 students who had experience with students with special needs in the teaching practice course. In the focus group interviews, the number of participants stated that experts could vary between 6 and 15 [28, 29]. In direct citations, the participants were given code names.

\section{Data collection tool}

The Multidimensional Attitude Scale for the Disabled developed by Findler, Vilchinsky and Werner [30] and adapted by Yelpaze and Türküm [31] into Turkish culture was used as a quantitative data collection tool. While the original form of the scale consisted of 34 items, the adapted scale consisted of 31 items; 14 in emotional dimension, 9 in cognitive dimension and 8 in behavioral dimension. The scale is a 5-point Likert and reliability analysis were performed according to the Cronbach $\alpha$ reliability coefficient in order to check the internal consistency of the scale answers. As a result of the analysis, Cronbach $\alpha$ value was found to be .72 in affective dimension, .78 in cognitive dimension and .77 in behavioral dimension.

The semi-structured interview form was used as a qualitative data collection tool. Semi-structured interviews are used as a comparative interview guide, and the researcher is expected to have sufficient objective knowledge about the phenomenon or experience being studied $[32,33]$. In this sense, the first author in charge has conducted special education courses and has studies on individuals with special needs. Focus group interviews were recorded to prevent data loss. After the raw data 
were transferred to the written medium, content analysis was performed.

\section{Data Analysis}

After the research data were loaded into SPSS 22 analysis program, skewness and kurtosis values were examined in order to test the normality of the data. Data with skewness and kurtosis values between +1.5 and 1.5 can be analyzed by parametric tests [34]. Since the skewness and kurtosis values of the subscales of the attitude scale towards disabled individuals were within the reference ranges, parametric tests were used. Independent samples t test was used for paired comparisons and one way anova was used for multiple comparisons. Scheffe, one of the post hoc tests, was used to determine which group was the difference. Significance level was accepted as $\mathrm{p}<0.05$.

In the qualitative part of the research, after the focus group interviews with the participants were transferred to the written medium, descriptive and content analysis was performed on the texts. In content analysis, it is aimed to reach the relationships that can explain the data obtained and to convey them to the reader [35]. In this research, themes were determined as a result of content analysis and direct quotations of the participants were given to support these themes. Themes were created by taking into consideration the similar and different views of the focus groups, which were formed according to the participants' special education courses and their contact with individuals with special needs.

\section{Results}

In this part of the research, quantitative and qualitative findings are given separately.

Qualitative results

Theme 1. Inability to describe feelings

In the three focus group interviews, participants stated that their emotional state was very diverse when they met individuals with special needs in social life. The participants stated that they had many different feelings such as sadness, helplessness, unfairness, inequality, feeling of help, embarrassment, calmness, empathy, purity, cleanliness. The participants said that they felt not only one emotion but also opposite emotions at the same time. One of the participants, Necati said, "I feel peaceful and helpless at their side. The reason I feel peaceful is that they have pure and clean feelings, and the reason I feel helpless is the feeling of not being able to do anything for them." Another participant, Semiha, expressed her complex feelings as follows. "The feeling of helplessness towards the disabled individual, the fact that there are few things to do against his or her pain causes me to be indecisive about how I should act, including the inclusion of an activity that the mentally and physically disabled individual cannot do." The difference in focus group interviews can be seen from the expressions that the students who make contact with individuals with special needs due to the teaching practice course undergo emotional change according to those who take the special education course. After taking special education course, they stated that they know the types of disability a little better and then they changed their perspectives after communication with the students with special needs in teaching practice. They expressed that there was much more they could do for them in the teaching profession, rather than sadness, helplessness, and inability to help. As the knowledge and experience level of the participants increased, it was understood that emotion confusion decreased. They stated that the participants could attend the classes of individuals with special needs but could have fear, lack of knowledge and experience problems. Hatice, one of the participants, said: "I would gladly give a lecture if I could be useful enough and would be pleased with me. However, I have concerns about how to teach and how to communicate". It was observed that the emotions such as fear and anxiety of the participants who took the lessons of individuals with special needs turned into feelings of happiness, peace and feeling useful.

\section{Theme 2. Positive attiude}

In the three focus group interviews, it was understood from the participant statements that the students attending physical education and sports teachers have positive attitudes towards disabled individuals. In the focus group, which consists of students who do not take special education courses and have less knowledge about disabled individuals, all participants stated that they have positive attitudes towards individuals with special needs and can give lectures with pleasure. Participants who took special education course and contacted individuals with special needs in their teaching experience stated that their attitudes were positive. Some participant statements have a positive attitude.

Selim: I think I can make good friends. I have a disabled friend. I even have a childhood friend. I can never have a prejudice. Aren't we all human? We may all have some differences."

Ayșe: "I don't have any prejudices about them even though I don't have a disabled friend."

İrem: "I don't have a disabled friend, but my relationships with other friends would be the same as them. I don't think I have any prejudice."

The participants stated that they could be friends with disabled people and they did not have any prejudices. They said that they can work in special education schools or in schools with special needs. The participants of the internship in the special education school stated that their attitudes and thoughts towards students with moderate and severe mental disabilities were improved and they did not have as much problems as they thought before.

\section{Theme 3. Feeling useful}

The participants who had contact with the students with special needs in the teaching experience course stated that after the lessons there was a sense of giving themselves a useful service for the society. Focus group participants who had not previously taught with individuals with special needs expressed that they would feel happy if they taught them. The participants expressed their feelings as follows. Selim said, "We owe them both social and individual lives, and I will be happy to do so." 
Nilay said, "At least I am very happy to add something to them. Nothing will make me as happy as bringing them to life." It is understood from the teacher's statements that the feeling of self-help of the participants was further strengthened after the teaching practice. When they saw that the mainstreaming students were happy in the mainstreaming classes in the teaching experience course, they stated that the participants felt better and fulfilled their duties completely. One of the participants Selin said, "The time I spend with them makes me feel like I've done something really remarkable in this life. It makes me think I've done something good with every smile. " Another participant, Hasan, "To see that they are happy makes me spiritually reach a different peace." In all three focus group interviews, it was observed that the idea of giving lessons to the students with special needs would make them happier than the normal students.

\section{Theme 4. Insufficient information}

In the 3 focus group interviews, the participants stated that they did not consider themselves sufficient about individuals with special needs, disability types, teaching adaptations, teaching methods and techniques. It is understood from the statements that the participants who do not take special education course have little knowledge about individuals with special needs. Although they have positive thoughts about individuals with special needs, insufficient knowledge about them indicates that participants cause some concerns and fears. Necati, one of the participants, expressed the inadequacy of his own level of knowledge and the feeling that this situation creates in himself. "I feel inadequate about disabled people. I don't know how to teach them. I think it would be very difficult so I feel a little nervous." The participants who took the special education course stated that their knowledge level increased a little but they could not give comfort to the individuals with special needs. They said it would be better if there was a more practice-oriented lesson in which the hours of special education should be more. One of the participants, Ahmet said, "Special education course gives us some things, but it is not enough that we need to demonstrate what we have learned theoretically in practice" and he claims that the structure of the special education course needs to change. The participants who have taught in the teaching experience with the students with special needs stated that they had some difficulties in adapting the activities to the mainstream students. They stated that they had the opportunity to work with these students because their internship in the teaching experience course was a special education school. The participants stated that the teaching experience should be given the opportunity to take lessons at special education school or mainstream students. The participants of the internship at the special education school stated that the special education course was inadequate and became more apparent during the practice. It is understood from the expressions that they have problems in adapting the activity according to student level. The participants stated that the practical part of the special education course should be. In this sense, it is understood that special education course is required but they do not receive theoretically fully equipped information and the application department is not sufficient.

\section{Quantitative results}

When Table 1 is analyzed, there is not a statistically significant difference between emotional $(\mathrm{t}=-.094, \mathrm{p}=$ $.925)$, thought $(\mathrm{t}=-.183, \mathrm{p}=.855)$ and attitude $(\mathrm{t}=-.741$, $\mathrm{p}=.460$ ) dimensions according to gender.

Table 2 was determined statistically significant in terms of emotional $(\mathrm{t}=1,000, \mathrm{p}=.318)$, thought $(\mathrm{t}=-1.381, \mathrm{p}$ $=.169)$ and attitude $(\mathrm{t}=-.174, \mathrm{p}=.862)$ according to the variable of being close to disabled.

According to the results of the Anova test, it was found that there was a statistically significant difference between the dimensions of thought and behavior among the students who did not take special education course, those who took special education course and who had contact with students with special needs in the teaching experience course. According to the post-hoc test results, it was found that there is a significant difference between the groups that make contact with the individuals with special needs and the other two groups. It was determined that the thought scores of the students of physical education and sports teachers increased positively when they took special education course and then contacted individuals with special needs. On the other hand, it was found that there was a difference between the first two students who did not take special education course with the other two groups. It was found that after taking special education course, behavior scores decreased.

\section{Discussion}

When the findings were examined, it was found that there was no statistically significant difference in the quantitative data according to the gender variable. Similarly, when qualitative data were examined, attitudes were similar in both genders. While it is thought that

Table 1. Independent T Test Results by Gender Variable

\begin{tabular}{llllllll}
\hline Sub Dimensions & Gender & $\mathbf{n}$ & $\bar{X}$ & SS & SH & t & $\boldsymbol{p}$ \\
\hline \multirow{2}{*}{ Emotional } & Male & 130 & 2.73 & 0.43 & 212 & -.094 & .925 \\
\multirow{2}{*}{ Thought } & Female & 84 & 2.74 & 0.39 & & & \\
& Male & 130 & 3.40 & 0.76 & 212 & -.183 & .855 \\
Attitude & Female & 84 & 3.42 & 0.72 & & & \multirow{2}{*}{. } \\
& Male & 130 & 2.66 & 0.46 & \multirow{2}{*}{212} & -.741 & .460 \\
\hline
\end{tabular}


Table 2. Independent Sample T Test Results According to Status of Disabled Relatives

\begin{tabular}{|c|c|c|c|c|c|c|c|}
\hline Sub Dimensions & Being disabled relatives & $\mathbf{n}$ & $\bar{x}$ & SD & SE & $\mathbf{t}$ & $p$ \\
\hline \multirow{3}{*}{ Emotional } & Non relative & 158 & 2.75 & .39739 & \multirow{3}{*}{212} & \multirow{3}{*}{1.000} & \multirow{3}{*}{.318} \\
\hline & & & & & & & \\
\hline & Relative & 56 & 2.69 & .47148 & & & \\
\hline \multirow{3}{*}{ Thought } & Non relative & 158 & 3.36 & .74370 & \multirow{3}{*}{212} & \multirow{3}{*}{-1.381} & \multirow{3}{*}{.169} \\
\hline & & & & & & & \\
\hline & Relative & 56 & 3.52 & .73392 & & & \\
\hline \multirow{3}{*}{ Attitude } & Non relative & 158 & 267 & .45854 & \multirow{3}{*}{212} & \multirow{3}{*}{-.174} & \multirow{3}{*}{.862} \\
\hline & & & & & & & \\
\hline & Relative & 56 & 2.68 & .42437 & & & \\
\hline
\end{tabular}

Table 3. One Way Anova Results by Taking Special Education Course and Contacting Students with Special Needs

\begin{tabular}{|c|c|c|c|c|c|c|c|}
\hline Sub Dimensions & Course Status & $\mathbf{n}$ & $\bar{x}$ & SD & $\begin{array}{l}\text { Anova } \\
\text { f }\end{array}$ & p & Scheffe \\
\hline \multirow{3}{*}{ Emotional } & $\begin{array}{l}\text { Not taking special } \\
\text { education course (1) }\end{array}$ & 82 & 2.8034 & .40435 & \multirow{3}{*}{2.117} & \multirow{3}{*}{.123} & \multirow{3}{*}{-} \\
\hline & $\begin{array}{l}\text { Taking special } \\
\text { education course (2) }\end{array}$ & 84 & 2.7232 & .39532 & & & \\
\hline & $\begin{array}{l}\text { Contact with } \\
\text { students with special } \\
\text { needs (3) }\end{array}$ & 48 & 2.6510 & .46697 & & & \\
\hline \multirow{3}{*}{ Thought } & $\begin{array}{l}\text { Not taking special } \\
\text { education course (1) }\end{array}$ & 82 & 3.0488 & .68570 & \multirow{3}{*}{33.193} & \multirow{3}{*}{.000} & \multirow{3}{*}{$\begin{array}{l}2>1 \\
3>1,2\end{array}$} \\
\hline & $\begin{array}{l}\text { Taking special } \\
\text { education course (2) }\end{array}$ & 84 & 3.4119 & .66630 & & & \\
\hline & $\begin{array}{l}\text { Contact with } \\
\text { students with special } \\
\text { needs ( } 3 \text { ) }\end{array}$ & 48 & 4.0125 & .55453 & & & \\
\hline \multirow{3}{*}{ Attitude } & $\begin{array}{l}\text { Not taking special } \\
\text { education course (1) }\end{array}$ & 82 & 2.8872 & .48734 & \multirow{3}{*}{22.447} & \multirow{3}{*}{.000} & \multirow{3}{*}{$\begin{array}{l}1>2,3 \\
2>3\end{array}$} \\
\hline & $\begin{array}{l}\text { Taking special } \\
\text { education course (2) }\end{array}$ & 84 & 2.6220 & .38855 & & & \\
\hline & $\begin{array}{l}\text { Contact with } \\
\text { students with special } \\
\text { needs (3) }\end{array}$ & 48 & 2.4010 & .27767 & & & \\
\hline
\end{tabular}

women can take more emotional approaches, it is seen that people of both sexes approach the disabled individuals with complex feelings and even feel helpless. In addition, it was understood from the statements that participants of both genders had positive attitudes towards disabled individuals. In the focus group, which consists of students who do not take special education courses and have less information about disabled individuals, all participants stated that they have positive attitudes towards individuals with special needs and that they can teach them fondly in inclusion programs. In the quantitative part of the study, it is seen that there is a similarity between the findings of thought dimension and qualitative findings. However, the behavioral dimension of the students' quantitative data was low. In the qualitative part of the research, students who have experience stated that they had problems in adapting teaching with individuals with special needs. Although it has been concluded that prospective teachers have positive opinions in both qualitative and quantitative findings, it is understood that there are some problems in practice. In this sense, it is possible to say that gender has no effect on attitude levels. Some studies support this $[25,36,37]$. When the quantitative data were examined according to the variable of being a relative of the disabled, no statistically significant difference was found. Although there was no prejudice in all variable groups, it was seen in the qualitative data that emotions could not be controlled and sometimes people were vacillated. In contrast to the quantitative data, the participants stated that the students with disabilities in the immediate 
environment could control their emotions more easily because they accepted the situation as normal and they could show this in their behavior. It was concluded that students with disabilities in their immediate environment would be able to give this education easily compared to other groups by taking the "Special Education" course in the license, which is positive in terms of inclusive education. The importance of effective time spent with people with disabilities has emerged in addition to taking special education lessons. The importance of the course is clearly underlined, but both qualitative and quantitative data reveal that the content is not sufficient and the scope should be expanded. The fact that there is no other compulsory or elective course similar to the special education course and the current course being theoretical also narrows the target gains. Ilgar [20] mentioned that it is important for prospective teachers to be able to receive trainings in the process of their learning and to increase the number of compulsory courses in order to develop skills in communicating with children with special needs. Similarly, it is still a matter of controversy that even with the comments abroad, this course alone is not sufficient and especially the whole course content cannot be used in practice $[38,39]$. When all these situations are interpreted according to the status of taking special education course, those who do not take special education course, who take special education course and who have contact with students with special needs in the teaching experience course completely coincide with the qualitative data that emerged statistically between the dimensions of thought and behavior between students of physical education and sports teachers. There has been a positive change in the dimension of thought in prospective teachers who have contact with individuals with special needs and have experience. The reason for this is thought to be that they are aware of individuals with special needs because they took special education courses and spent time with them. As a matter of fact, in the qualitative data of the research, pre-service teachers stated that after taking special education lesson, they perceived the needs of individuals with special needs better. In this sense, qualitative and quantitative findings support each other. It is supported by researches that special education courses and practices affect attitudes towards individuals with special needs positively $[24,40]$.

The finding that draws attention in the quantitative data of the study is that the behavior dimension of the teacher candidates according to their status of taking lessons against individuals with special needs is differentiated against those who take special education courses and students with special needs experience. As the grade level increased and the experience experienced, there was a decrease in the dimension of behavior. When the reasons for this are considered, it can be shown that their special education course is inadequate and remains in theory only. It can be said that the candidate teachers' behaviors have negative effects on how to communicate with individuals with special needs, problems such as classroom dominance and teaching adaptations in the school experience. In qualitative interviews, candidate teachers who have experience with individuals with special needs stated that they had the most problems in teaching adaptation in the focus group interview. In studies related to special needs students and mainstreaming education, it is stated that there is often lack of information $[10,22]$ and inadequacies in teaching adaptations [10,41]. The most important reason for these problems is the lack of content and scope of the special education course. Practices without sufficient knowledge and equipment are likely to adversely affect the attitudes of teachers and prospective teachers. Many researchers have expressed ideas about expanding the scope and content of the special education course $[24,38,40]$.

\section{Conclusion}

As a result of the research, it was found that physical education teachers had a good attitude in thought dimension and a low attitude in emotional and behavior dimension. It was concluded that while thinking dimension increased according to taking special education course and experience, it decreased in attitude dimension. In the dimension of thought, it was concluded that taking a special education course and being experienced had a positive effect. It is thought that the low level of attitude in the dimension of attitude is caused by the candidate teachers' feeling inadequate.

According to the results of the research, it is suggested that the content and content of the special education course given to the prospective physical education teachers should be regulated. However, legal regulations may be proposed in order to provide practical training by increasing the course hours. Within the scope of the special education course, prospective teachers can work with the students with special needs and make internship practices compulsory for them to have experience.

\section{Conflict of interest}

The authors report no conflict of interest. 


\section{References}

1. Coleman D. Assisted suicide and disability. Human Rights: Journal of the Section of Individual Rights and Responsibilities, 2000; 27 (1): 1-11.

2. Whyte SR, Ingstad B. Disability and culture: An overview. Whyte SR, Ingstad B. (Eds.). Disability and culture. California: University of California Press; 1995.

3. WHO. International classification of impairments, disabilities and handicaps. Geneva: World Health Organisation; 1980.

4. Finkelstein V. Disabling Society: Enabling Interventions. Workbook 4. K255 The Disabling Society. Open University; School of Health, Welfare and Community Education; 1995.

5. WHO. WHO Global Disability Action Plan 2014-2021: Better Health For All People With Disability, 2014.

6. Turkey. Republic of Turkey Ministry of National Education. Ministry of National Education Statistics; . [Internet]. 2019. [cited 2019 Jul 20]. Available from: http://sgb.meb.gov.tr/ meb_iys_dosyalar/2019_09/06141052 meb istatistikleri orgun_egitim_2018_2019.pdf, 2019

7. Sucuoğlu B, Kargın T. Inclusive Practices in Primary Education. İstanbul: Morpa Culture Publications; 2006.

8. Kınalı G. Mentally Handicapped Body-Painting-Music Education. Different Developing Children. İstanbul: Epsilon Publications: 2003.

9. Koçyiğit S, Tuğluk MN, Kök M. Play as educatıonal activtiy in the child's development Process Journal of Atatürk University Kazım Karabekir Education Faculty, 2007; 16: 324-342.

10.Demirci PT, Çınar İ, Demirci N. Studying the problems of Primary School Teachers Derived from inclusive education and physical education programme of The students in need of Special Education, International Journal of Turkish Education Sciences (IJTES), 2014; 2(2): 136-150.

11.Niesyn ME. Strategies for success: Evidencebased instructional practices for students with emotional and behavioral disorders. Preventing School Failure, 2009; 53(4): 227- 233. https://doi.org/10.3200/PSFL.53.4.227-234

12.Zeybek Ö. Opinions and suggestions of English teachers in primary schools about inclusive education [Master thesis]. Eskişehir: Anadolu University, Institute of Educational Sciences; 2015.

13.Gündüz A. Teacher Opinions on Academic Successes of the First Grade Mainstreamed Students in the Private and State Primary Schools, [Master Thesis]. Çanakkale: Çanakkale Onsekiz Mart University, Institute of Educational Sciences; 2015.

14.Akalin S. Opinions and Needs of Mainstream Classroom Teachers About Classroom Management. Ankara University Faculty of Educational Sciences Journal of Special Education, 2015; 16(03): 215-236. http://doi.org/10.21565/auebfoed.24224

15.Engin AO, Tösten R, Kaya M. D, Köselioğlu YS. The Evaluation of Manners and Point of Views Related to Mainstreaming Education Having Responsibilities of Students Who are in Needs of Special Education for Primary Education (Example of Kars), Kafkas University Journal of the Institute of Social Sciences, 2014; 13 (1): 27-44. https://doi.org/10.9775/kausbed.2014.003

16. Yatgin S, Sevgi HM, Uysal S. Classroom Teachers' Opinions On Inculusive Education And Investigation Of Their Occupational Burnout According To Various Variables, Abant İzet Baysal University Journal of Faculty of Education, 2015; 15 (Special Number): 167- 180. https://doi.org/10.17240/aibuefd.2015.15.0-5000128650
17.Mdikana A, Ntshangase S, Mayekiso T. Pre-Service Educators' Attitudes towards Inclusive Education. International Journal of Special Education, 2007; 22(1): 125-131.

18.Babaoğlan E, Yılmaz Ş. Competency of classroom teachers in the inclusive education. Kastamonu Education Journal, 2010; 18(2): 345-354.

19.Demirezen S, Akhan NE. The opinions of the social studies teachers on inclusion practices. Abant Izzet Baysal University Journal of Faculty of Education, 2016; 16:1206-1223.

20.İlgar Ş. An Investigation of the Awareness of Teacher Candidates About Children with Special Needs (IU Hasan Ali Yücel Faculty of Education Sample), HAYEF Journal of Education, 2017; 14(1): 313-338.

21.Erişkin A, Kıraç S, Ertuğrul Y. Assesment of inclusion practices by general education teachers. Journal of Education and Social Sciences, 2012; 41(193): 200-213.

22.Sadioğlu Ö. A Qualitative Study of Primary School Teachers' Problems Expectations and Suggestions Related to Inclusive Education [Phd Thesis]. Bursa Uludağ University, Institute of Education Sciences; 2011.

23.Karademir T, Açak M, Türkçapar Ü, Eroğlu H. Determination Of Physical Education Teacher Candidates' Attitudes Towards Mental Disability. Journal of Physical Education and Sport Sciences, 2018; 20(3): 103-112.

24.Özer D, Süngü B. "Adapted Physical Education" A Practical Course From The Perspective of PreService Physical Education Teachers, Hacettepe Journal of Sport Sciences, 2016; 27 (1): 1- 15. https://doi.org/10.17644/sbd.251309

25.Açak M, Karakaya YE, Tan Ç, Coşkuner Z. Investigation of the Attitudes of Students from Exercise and Sports Education For Individuals With Disabilities Department Toward Individuals With Disabilities. Turkish Studies; 2016; 1: 1-8.

26.Creswell JW, Clark VLP. Designing and conducting mixed methods research (3rd ed). Ankara: An1 Publishing; 2018.

27.Marshall C, Rossman GB. Designing qualitative research. $\left(5^{\text {th }}\right.$ ed) Sage publications; 2014

28. Byers PY, Wilcox JR. Focus groups: a qualitative opportunity for researchers. Journal of Business Communication, 1991; 28 (1): 63-78. https://doi.org/10.1177/002194369102800105

29.Howard E, Hubelbank J, Moore P. Employer evaluation of graduates: use of the focus group. Nurse Educator, 1989; 14 (5): 38-41. https://doi.org/10.1097/00006223-198909000-00019

30.Findler L, Vilchinsky N, Werner S. The multidimensional attitudes scale toward persons with disabilities (MAS): Construction and validation. Rehabil Couns Bull, 2007; 50: 166-176. doi:10.1177/00343552070500030401

31.Yelpaze İ, Türküm A. Adaptation and Validation of Turkey Version of Multidimensional Attitudes toward Persons with Disabilities. OPUS-International Journal of Society Researches, 2018; 8 (14): 167-187. https://doi.org/10.26466/opus.377906

32.McIntosh MJ, Morse J.M. Situating and constructing diversity in semistructured interviews. Global Qualitative Nursing Research, 2015; 2:1- 12. https://doi.org/10.1177/2333393615597674

33. Morse JM, Field PA. Qualitative research methods for health professionals (2nd ed). Thousand Oaks, CA: SAGE; 1995.

34.Tabachnick BG, Fidell LS. Using multivariate statistics (5th ed). Boston: Allyn and Bacon; 2007.

35.Yıldırım A, Şimşek H. Qualitative Research Methods in 
Social Sciences. Ankara: Seçkin Publicitions; 2016.

36.Özcan GH. Examination of the Factors Affecting the Attitudes of Physical Education and Sports Teachers towards Mentally Retarded Children [Master thesis]. İstanbul: Gedik University Institute of Health Sciences; 2016.

37.Jerlinder K, Danermark B, Gill P. Swedish PrimarySchool Teachers' Attitudes to Inclusion - The Case of PE and Pupils with Physical Disabilities. European Journal of Special Needs Education, 2009; 25(1): 45-57. https://doi.org/10.1080/08856250903450830

38.Perlman D, Piletic C. The Influence of an Adapted Physical Education Course on Preservice Teacher Instruction: Using a Self-Determination Lens. AJTE, 2012;37. https://doi.org/10.14221/ajte.2012v37n1.6/

39.Hardin B. Physical education teachers' reflections on preparation for inclusion. Physical Educator, 2005; 62 (1): 44-56.

40.Hodge SR, Tannehil D, Kluge MA. Exploring the meaning of practicum experiences for PETE students in Adapted Physical Activity Quarterly. Human Kinetics, 2003; 20: 381- 399. https://doi.org/10.1123/apaq.20.4.381

41.Ceylan F. Determinig the prevention and intervention strategies carried out by primary school teachers intended for the problem behaviors encountered on inclusive students [Unpublished master's thesis]. Bolu: Abant İzzet Baysal University, Institute of Educational Sciences; 2015. https://doi.org/10.1097/00006223-198909000-00019

\section{Information about the authors:}

Emrah Aykora; (Corresponding author); http://orcid.org/0000-0003-1225-9231; eaykora@gmail.com; Faculty of Sport Science, University of Çanakkale Onsekiz Mart; Çanakkale, Turkey.

Sinan Uğraş; http://orcid.org/0000-0003-0792-1497; sinanugras@gmail.com; Faculty of Sport Science, University of Çanakkale Onsekiz Mart; Çanakkale, Turkey.

\section{Cite this article as:}

Emrah Aykora, Sinan Uğraș. Investigating the attitudes of special educated physical education prospective teachers towards disabled people. Physical education of students, 2020;24(1):11-18.

https://doi.org/10.15561/20755279.2020.0102

This is an Open Access article distributed under the terms of the Creative Commons Attribution License, which permits unrestricted use, distribution, and reproduction in any medium, provided the original work is properly cited http://creativecommons.org/licenses/by/4.0/deed.en

Received: 26.10 .2019

Accepted: 17.11.2019; Published: 04.02.2020 